\title{
Crystalline and Electronic Structures and Magnetic and Electrical Properties of La-Doped $\mathrm{Ca}_{2} \mathrm{Fe}_{2} \mathrm{O}_{5}$ Compounds
}

\author{
T.L. PHAN,${ }^{1}$ P.T. THO,${ }^{1}$ N. TRAN,${ }^{1}$ D.H. KIM,${ }^{1}$ B.W. LEE,${ }^{1,4}$ D.S. YANG,${ }^{2}$ \\ D.V. THIET, ${ }^{3}$ and S.L. $\mathrm{CHO}^{3}$ \\ 1.-Department of Physics and Oxide Research Center, Hankuk University of Foreign Studies, \\ Yongin 449-791, South Korea. 2.-Department of Science Education, Chungbuk National \\ University, Cheongju 360-763, South Korea. 3.-Department of Physics, University of Ulsan, \\ Ulsan 680-749, South Korea. 4.-e-mail: bwlee@hufs.ac.kr
}

\begin{abstract}
Brownmillerite $\mathrm{Ca}_{2} \mathrm{Fe}_{2} \mathrm{O}_{5}$ has been observed to exhibit many outstanding properties that are applicable to ecotechnology. However, very little work on doped $\mathrm{Ca}_{2} \mathrm{Fe}_{2} \mathrm{O}_{5}$ compounds has been carried out to widen their application scope. We present herein a detailed study of the crystalline/geometric and electronic structures and magnetic and electrical properties of $\mathrm{Ca}_{2-x} \mathrm{La}_{x} \mathrm{Fe}_{2} \mathrm{O}_{5}$ $(x=0$ to 1$)$ prepared by conventional solid-state reaction. X-ray diffraction patterns indicated that the compounds with $x=0$ to 0.05 exhibited brownmillerite-type single phase. La doping with higher content $(x \geq 0.1)$ stimulated additive formation of Grenier- $\left(\mathrm{LaCa}_{2} \mathrm{Fe}_{3} \mathrm{O}_{8}\right)$ and perovskite-type $\left(\mathrm{LaFeO}_{3}\right)$ phases. Extended x-ray absorption fine structure spectroscopy at the $\mathrm{Fe}$ $\mathrm{K}$-edge and electron spin resonance spectroscopy revealed presence of $\mathrm{Fe}^{3+}$ in the parent $\mathrm{Ca}_{2} \mathrm{Fe}_{2} \mathrm{O}_{5}(x=0)$ and both $\mathrm{Fe}^{3+}$ and $\mathrm{Fe}^{4+}$ in the doped compounds $(x \geq 0.05)$. The $\mathrm{Fe}^{4+}$ content tended to increase with increasing $x$. This stimulates ferromagnetic exchange interactions between $\mathrm{Fe}^{3+}$ and $\mathrm{Fe}^{4+}$ ions and directly influences the magnetic properties of $\mathrm{Ca}_{2-x} \mathrm{La}_{x} \mathrm{Fe}_{2} \mathrm{O}_{5}$. Electrical resistivity $(\rho)$ measurements in the temperature range of $T=20 \mathrm{~K}$ to $400 \mathrm{~K}$ revealed that all the compounds exhibit insulator behavior; the $\rho(T)$ data for $x \geq 0.1$ could be described based on the adiabatic small polaron hopping model.
\end{abstract}

Key words: Brownmillerite-type oxides, crystal structure, magnetic properties, electrical properties

\section{INTRODUCTION}

In recent years, $\mathrm{Ca}_{2} \mathrm{Fe}_{2} \mathrm{O}_{5+\delta}$ with $\delta=0$ has attracted intensive interest from research groups, because of its novel properties applicable to ecotechnology, such as its suitability for reliable resistiveswitching memory, ${ }^{1}$ electrochemical energy conversion devices (i.e., solid-oxide fuel cells and metal air batteries), ${ }^{2}$ gas sensors, ${ }^{3}$ chemical looping $\mathrm{H}_{2}$ production, ${ }^{4}$ and reversible $\mathrm{CO}_{2}$ capture for air purification. ${ }^{5}$ At room temperature, it has brownmilleritetype orthorhombic structure in space group Pcmn with lattice constants $a=5.425 \mathrm{~A}, b=14.769 \mathrm{~A}$,

(Received July 17, 2017; accepted September 27, 2017;

published online October 16, 2017) and $c=5.598 \AA \AA^{6,7}$ This structure can be described as alternating layers of corner-sharing $\mathrm{FeO}_{6}$ octahedra and $\mathrm{FeO}_{4}$ tetrahedra. The $\mathrm{Fe}^{3+}$ spins are nearly directed along the $c$ axis, leading to $G$-type antiferromagnetic (AFM) order and weak ferromagnetism in $\mathrm{Ca}_{2} \mathrm{Fe}_{2} \mathrm{O}_{5} \cdot{ }^{3,8}$

Detailed investigation of its thermal expansion has revealed that this compound exhibits several transitions, ${ }^{8-10}$ including an antiferromagneticparamagnetic (AFM-PM) transition at $T_{\mathrm{N}} \approx 725 \mathrm{~K}$ (the Néel temperature), transformation of the original Pcmn structure to a body-centered structure at $\sim 970 \mathrm{~K}$, an incommensurate modulated transition caused by lattice expansion in the $\mathbf{a}$ and $\mathbf{c}$ directions at $\sim 1180 \mathrm{~K}$, and significant lattice contraction along the $\mathbf{b}$ direction at $\sim 1308 \mathrm{~K}^{10}$ These transitions can change the oxygen content $(\delta)$, and 
result in two symmetry types with left and right $\mathrm{FeO}_{4}$ tetrahedral chains along the c axis in the same layer. ${ }^{9,10}$

In terms of its electrical properties, $\mathrm{Ca}_{2} \mathrm{Fe}_{2} \mathrm{O}_{5}$ is an insulator and considered as a model system for understanding oxygen-ion-related conductivity. A large change in the oxygen content of $\mathrm{Ca}_{2} \mathrm{Fe}_{2} \mathrm{O}_{5+\delta}$ with $\delta=1$ results in formation of the end system $\mathrm{CaFeO}_{3}$ (with perovskite-type structure of $\left.A B \mathrm{O}_{3}\right),{ }^{11,12}$ and a metal-insulator transition at $\sim 290 \mathrm{~K}^{13}$ The electrical conductivity of $\mathrm{Ca}_{2} \mathrm{Fe}_{2} \mathrm{O}_{5}$ has been found to be enhanced by $\mathrm{N}$ doping ${ }^{2}$ or $(\mathrm{Mg}, \mathrm{Al})$ codoping. ${ }^{14}$ More recently, Dhankhar and coworkers found anomalous magnetoresistance below the $T_{\mathrm{N}}$ of $\mathrm{Ca}_{2} \mathrm{Fe}_{2} \mathrm{O}_{5}$, and a memory effect when measuring the resistivity under an external magnetic field. ${ }^{15}$

Though promising applications of this material system have already been demonstrated, very little work on rare-earth-doped $\mathrm{Ca}_{2} \mathrm{Fe}_{2} \mathrm{O}_{5}$ materials has been carried out. ${ }^{2,14,16}$ Additionally, systematic studies of the structural/geometric, electronic, magnetic, and electrical properties have not yet been conducted. Assessment of their applicability for use in electronic devices is also still lacking. In this work, we prepared La-doped $\mathrm{Ca}_{2} \mathrm{Fe}_{2} \mathrm{O}_{5}$ compounds, then studied their crystal/geometric and electronic structures and magnetic and electrical properties. We suggest that La doping creates more holes (i.e., more $\mathrm{Fe}^{4+}$ ions), because of $\mathrm{La}^{3+}$ substitution for $\mathrm{Ca}^{2+}$ in $\mathrm{Ca}_{2-x} \mathrm{La}_{x} \mathrm{Fe}_{2} \mathrm{O}_{5}$. Our studies show that $\mathrm{La}$ doping causes structural phase separation and a change in the concentrations of $\mathrm{Fe}^{3+}$ and $\mathrm{Fe}^{4+}$ ions. This influences the strength of the ferromagnetic (FM) exchange interactions between $\mathrm{Fe}^{3+}$ and $\mathrm{Fe}^{4+}$ ions as well as the electrical conductivity of the $\mathrm{Ca}_{2-x} \mathrm{La}_{x} \mathrm{Fe}_{2} \mathrm{O}_{5}$ compounds.

\section{EXPERIMENTAL PROCEDURES}

Polycrystalline $\mathrm{Ca}_{2-x} \mathrm{La}_{x} \mathrm{Fe}_{2} \mathrm{O}_{5}$ compounds $(x=0$ to 1) were fabricated by conventional solid-state reaction in air. Commercial powders of $\mathrm{CaO}, \mathrm{La}_{2} \mathrm{O}_{3}$, and $\mathrm{Fe}_{2} \mathrm{O}_{3}$ with purity of $99.9 \%$ were used as precursors. These powders were combined in stoichiometric amounts according to the nominal formula $\mathrm{Ca}_{2-x} \mathrm{La}_{x} \mathrm{Fe}_{2} \mathrm{O}_{5}$, then well mixed by using an agate pestle and mortar. The mixtures were then pressed into pellets and preannealed at $1373 \mathrm{~K}$ for $12 \mathrm{~h}$. After several intermediate applications of the grinding and preannealing processes at temperatures below $1523 \mathrm{~K}$, the final pellets were annealed once more at $1573 \mathrm{~K}$ for $24 \mathrm{~h}$. The crystal structure of the resulting products was checked by $\mathrm{x}$-ray diffractometer (Rigaku, MiniFlex) equipped with $\mathrm{Cu}$ $\mathrm{K}_{\alpha}$ radiation source (wavelength $\lambda=1.5406 \AA$ ). Notably, before taking x-ray diffraction (XRD) patterns, a small amount $(\sim 5 \mathrm{wt} . \%)$ of standard $\mathrm{Si}$ powder was mixed with all compounds, to minimize errors caused by position calibration of the incident x-ray beam. The electronic structure associated with the $\mathrm{Fe}$ absorbing atom $\left(E_{0}=7112 \mathrm{eV}\right)^{17}$ in $\mathrm{Ca}_{2-x} \mathrm{La}_{x} \mathrm{Fe}_{2} \mathrm{O}_{5}$ was studied by using x-ray absorption fine structure (XAFS) spectroscopy (Pohang Accelerator Laboratory, South Korea). Data in the x-ray absorption near-edge structure (XANES) region were collected in steps of $0.2 \mathrm{eV}$ to $0.5 \mathrm{eV}$. The XAFS data were analyzed using the IFEFFIT software package. For reference, we also recorded XAFS spectra of $\mathrm{Fe}_{3} \mathrm{O}_{4}$ (with a mixture of $\mathrm{Fe}^{2+}$ and $\mathrm{Fe}^{3+}$ ) and $\mathrm{Fe}_{2} \mathrm{O}_{3}\left(\mathrm{Fe}^{3+}\right)$, corresponding to $E_{0}$ values of about $7121 \mathrm{eV}$ and $7123 \mathrm{eV}$, respectively. Electron spin resonance (ESR) spectra were recorded from the powder compounds using a JEOL-TE300 spectrometer operating in the X-band frequency range at $f \approx 9.45 \mathrm{GHz}$. Magnetization $(M)$ versus magnetic field measurements were performed by vibrating-sample magnetometry (VSM), varying the magnetic field $(H)$ from $0 \mathrm{kOe}$ to $10 \mathrm{kOe}$. The electrical resistivity was measured in the temperature range of $T=20 \mathrm{~K}$ to $400 \mathrm{~K}$ by four-probe technique in van der Pauw configuration.

\section{RESULTS AND DISCUSSION}

\section{Crystalline, Local Geometric, and Electronic Structures}

Figure 1 shows the powder XRD patterns of all the $\mathrm{Ca}_{2-x} \mathrm{La}_{x} \mathrm{Fe}_{2} \mathrm{O}_{5}$ compounds, with fixed scan step of $0.01^{\circ}$. The XRD features reveal structural changes of $\mathrm{Ca}_{2-x} \mathrm{La}_{x} \mathrm{Fe}_{2} \mathrm{O}_{5}$ as $x$ was increased. This can be seen from the enlarged view of the diffraction peaks at around $31^{\circ}$ to $35^{\circ}$ in Fig. 2. Detailed analysis revealed that the compounds with $x=0$ and 0.05 completely crystallized with orthorhombic brownmillerite structure (in space group Pcmn), corresponding to the Miller-indexed peaks.

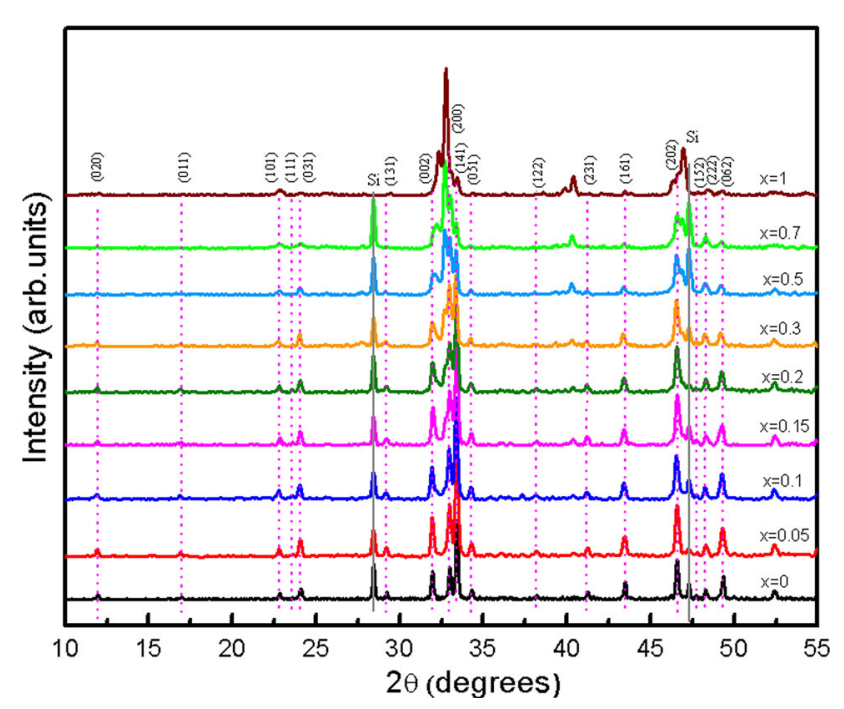

Fig. 1. Room-temperature XRD patterns of all $\mathrm{Ca}_{2-x} \mathrm{La}_{x} \mathrm{Fe}_{2} \mathrm{O}_{5+\delta}$ compounds prepared by solid-state reaction. The Miller-indexed peaks belong to the Pnma brownmillerite phase (dotted lines). Additional peaks without Miller indices are assigned to Grenier- and/ or perovskite-type phases. 
However, for $x \geq 0.1$, additional peaks started to appear and the brownmillerite peaks gradually disappeared. By comparison with the reference compounds (Fig. 2), we believe that the additive peaks are related to development of Grenier$\left(\mathrm{LaCa}_{2} \mathrm{Fe}_{3} \mathrm{O}_{8}\right)$ and/or perovskite-type $\left(\mathrm{LaFeO}_{3}\right)$ phases caused by the increase in oxygen content; Fig. 3 shows the 3D crystal geometry of three phase structures for comparison. This means that the general formula of our compounds must be rewritten as $\mathrm{Ca}_{2-x} \mathrm{La}_{x} \mathrm{Fe}_{2} \mathrm{O}_{5+\delta}$. In fact, $\mathrm{Ca}_{2} \mathrm{Fe}_{2} \mathrm{O}_{5}$ and $\mathrm{LaFeO}_{3}$ have been found to be two end members of $\mathrm{LaCa}_{2} \mathrm{Fe}_{3} \mathrm{O}_{8}$ (i.e., the $\mathrm{LaCa}_{2} \mathrm{Fe}_{3} \mathrm{O}_{8}$ structure is intermediate between the $\mathrm{Ca}_{2} \mathrm{Fe}_{2} \mathrm{O}_{5}$ and $\mathrm{LaFeO}_{3}$ structures), and the following process would happen during sample fabrication ${ }^{7,18,19}$ :

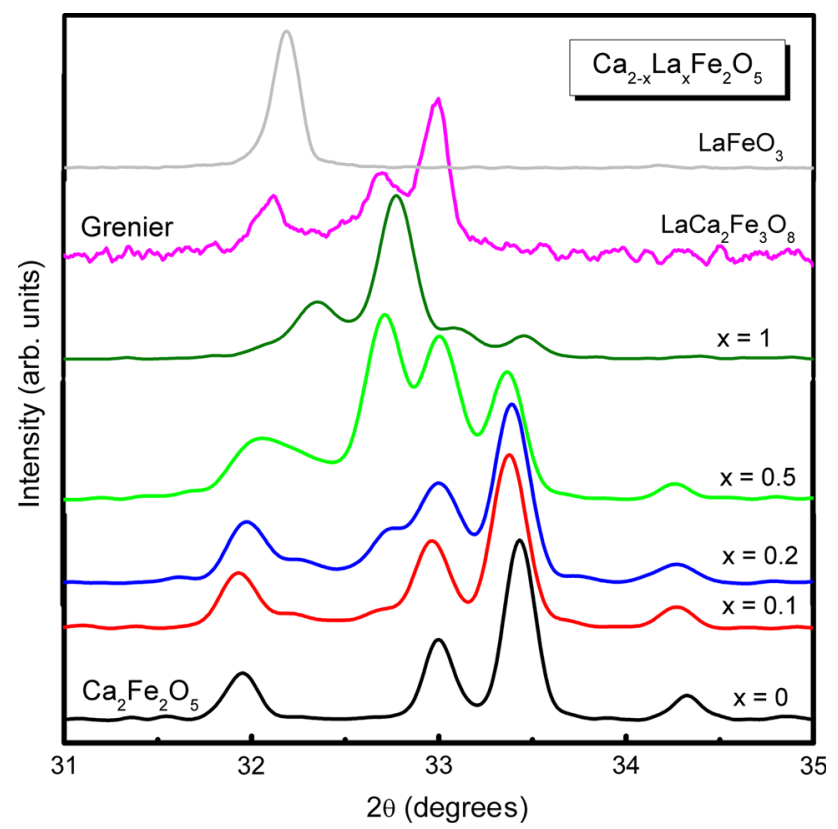

Fig. 2. Enlarged view of XRD patterns of $\mathrm{Ca}_{2-x} \mathrm{La}_{x} \mathrm{Fe}_{2} \mathrm{O}_{5+\delta}$ in the diffraction region of $31^{\circ}$ to $35^{\circ}$, compared with those of reference oxides $\mathrm{LaCa}_{2} \mathrm{Fe}_{3} \mathrm{O}_{8}$ and $\mathrm{LaFeO}_{3}$.

$$
\begin{aligned}
& a \mathrm{LaCa}_{2} \mathrm{Fe}_{3} \mathrm{O}_{8+z} \rightarrow b \mathrm{Ca}_{2} \mathrm{Fe}_{2} \mathrm{O}_{5}+b \mathrm{LaFeO}_{3} \\
& \quad+c \mathrm{LaCa}_{2} \mathrm{Fe}_{3} \mathrm{O}_{8+z^{\prime}},
\end{aligned}
$$

where $a=b+c, z$, and $z^{\prime}$ are variables. Coexistence of brownmillerite, Grenier, and/or perovskite phases in the compounds with $0.1 \leq x \leq 1$ leads to complex variation of the XRD patterns. Note that a small amount of Ca could partially substitute for La in perovskite $\mathrm{LaFeO}_{3}$, resulting in $\mathrm{La}_{1-y} \mathrm{Ca}_{y} \mathrm{FeO}_{3}$ type compounds, peak shifts, and secondary XRD peaks.

We additionally analyzed the brownmillerite phase in the compounds with $x=0$ to 0.2 , and determined the lattice parameters $(a, b, c)$ and unit cell volume $(V)$. The values of $a=5.424 \AA$, $b=14.761 \AA$, and $c=5.589 \AA$ determined for $\mathrm{Ca}_{2} \mathrm{Fe}_{2} \mathrm{O}_{5}(x=0)$ in Table I are in good agreement with those previously reported. ${ }^{6,7}$ With increasing $x$ from 0 to 0.1 , these parameters slightly increased, owing to replacement of $\mathrm{La}^{3+}$ with larger ionic radius $(1.16 \AA)$ for $\mathrm{Ca}^{2+}$ with smaller radius $(\sim 1.0$ $\AA$ ). However, increase of $x$ above 0.1 reduced the unit cell parameters, owing to formation of Grenier and perovskite phases. These results indicate that $x_{\mathrm{c}}=0.05$ is the concentration threshold for formation of brownmillerite $\mathrm{Ca}_{2-x} \mathrm{La}_{x} \mathrm{Fe}_{2} \mathrm{O}_{5}$ single-phase compounds. For other systems reported previously, such as $\mathrm{Ba}_{2}\left(\mathrm{In}_{1-x} \mathrm{Ga}_{x}\right)_{2} \mathrm{O}_{5},{ }^{20} \mathrm{Ba}_{2}\left(\mathrm{In}_{1-x} \mathrm{Al}_{x}\right)_{2} \mathrm{O}_{5},{ }^{21}$ and $\mathrm{Ca}_{2} \mathrm{FeAl}_{1-x} \mathrm{Mg}_{x} \mathrm{O}_{5},{ }^{14}$ brownmillerite single phase was also found for $x<0.2$. However, $\mathrm{Ca}_{2} \mathrm{Fe}_{2-x} \mathrm{Al}_{x} \mathrm{O}_{5}$-based brownmillerite compounds could be prepared with higher $x$ values, with $x_{\mathrm{c}} \approx 0.65{ }^{22}$ Synthesis of brownmillerite compounds with all $x$ values is very difficult and dependent on many experimental factors.

Variation of $x$ and $\delta$ in $\mathrm{Ca}_{2-x} \mathrm{La}_{x} \mathrm{Fe}_{2} \mathrm{O}_{5+\delta}$ also changed the valence state of $\mathrm{Fe}$, as revealed by XAFS spectroscopy. Figure 4 shows normalized Fe K-edge XANES spectra (upper panel) and their first derivative (lower panel) for the compounds with $x=0,0.1,0.3,0.5,0.7$, and 1 at room temperature.

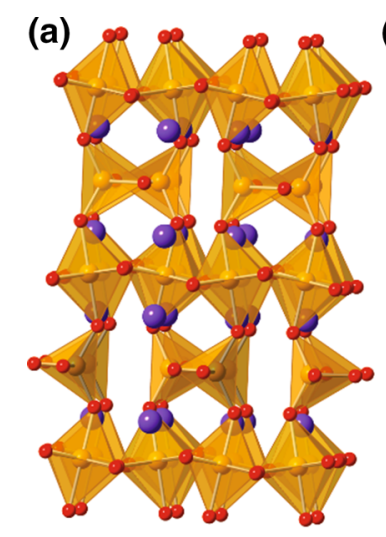

$\mathrm{Ca}_{2} \mathrm{Fe}_{2} \mathrm{O}_{5}$ (b)

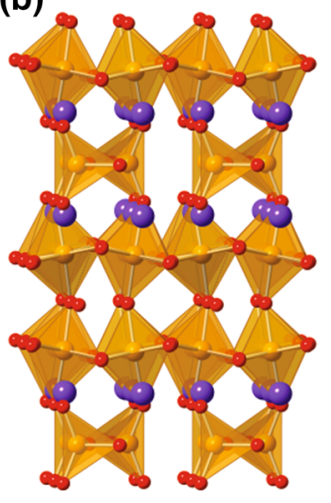

$\mathrm{LaCa}_{2} \mathrm{Fe}_{3} \mathrm{O}_{8}$ (c)

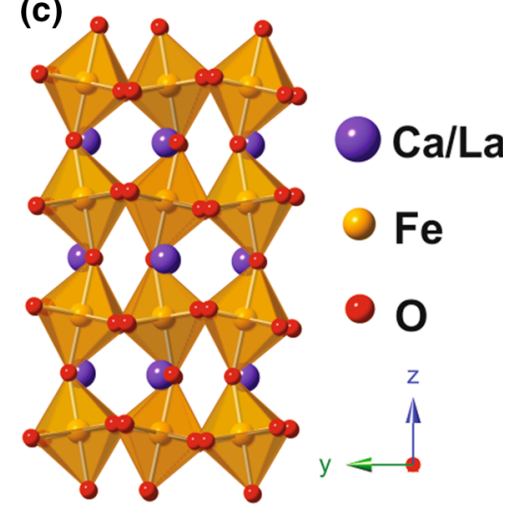

$\mathrm{LaFeO}_{3}$

Fig. 3. Crystal geometry of (a) brownmillerite $\mathrm{Ca}_{2} \mathrm{Fe}_{2} \mathrm{O}_{5}$, (b) Grenier $\mathrm{LaCa}_{2} \mathrm{Fe}_{3} \mathrm{O}_{8}$, and (c) perovskite $\mathrm{LaFeO}_{3}$ structures. 
Table I. Experimental values of some parameters determined by studying the crystalline and electronic structures and electrical and magnetic properties of La-doped $\mathrm{Ca}_{2} \mathrm{Fe}_{2} \mathrm{O}_{5}$ compounds. The structural parameters $(a, b, c$, and $V$ ) were only calculated for compounds that crystallized mainly in brownmillerite phase

\begin{tabular}{|c|c|c|c|c|c|c|c|}
\hline Compound & $a(\AA)$ & $b(\AA)$ & $c(\AA)$ & $V\left(\AA^{3}\right)$ & $E_{\exp }(e V)$ & $\boldsymbol{R}_{\mathrm{Fe}-\mathrm{O}}(\AA)$ & $E_{\mathbf{a}}(\mathbf{e V})$ \\
\hline$x=0$ & 5.424 & 14.761 & 5.589 & 447.48 & 7123.1 & 1.910 & - \\
\hline$x=0.05$ & 5.429 & 14.775 & 5.595 & 448.79 & - & - & - \\
\hline$x=0.1$ & 5.433 & 14.785 & 5.593 & 449.27 & 7123.3 & 1.924 & 123.8 \\
\hline$x=0.15$ & 5.427 & 14.780 & 5.592 & 448.54 & - & - & - \\
\hline$x=0.2$ & 5.421 & 14.786 & 5.594 & 448.39 & - & - & 98.0 \\
\hline$x=0.3$ & - & - & - & - & 7123.7 & 1.958 & 94.8 \\
\hline$x=0.5$ & - & - & - & - & 7123.9 & 1.958 & 97.4 \\
\hline$x=0.7$ & - & - & - & - & 7124.2 & 1.975 & 95.1 \\
\hline$x=1$ & - & - & - & - & 7124.9 & 2.001 & 104.6 \\
\hline
\end{tabular}

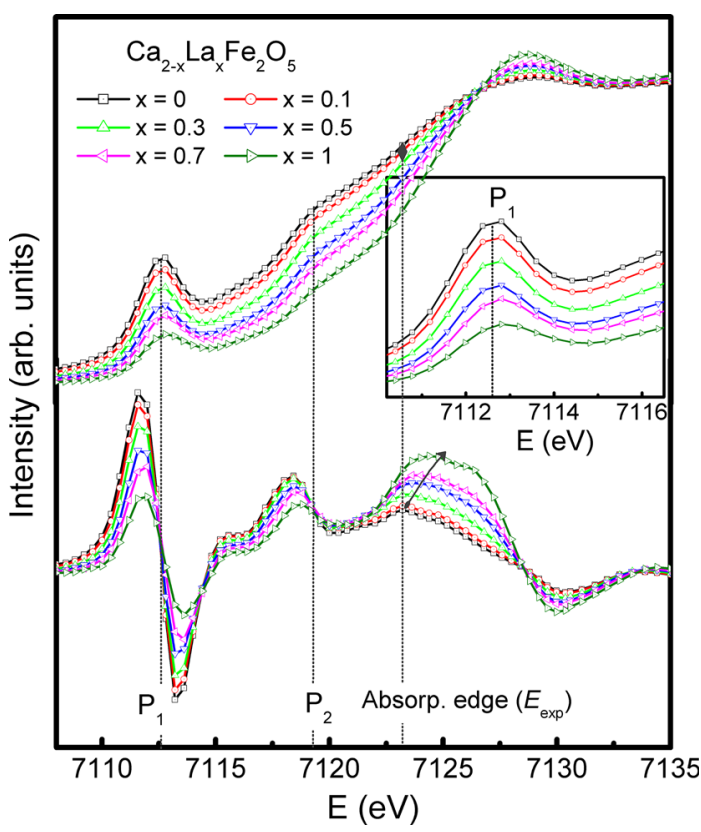

Fig. 4. Fe K-edge XANES spectra (upper panel) and their first derivative (lower panel) for typical $\mathrm{Ca}_{2-x} \mathrm{La}_{x} \mathrm{Fe}_{2} \mathrm{O}_{5+\delta}$ compounds. Inset shows enlarged view of pre-edge peak $\mathrm{P}_{1}$.

Careful analysis of the XANES spectra reveals three points of interest as follows:

(1) The intensity of the pre-edge peak (labeled $\mathrm{P}_{1}$ ) at around $7112 \mathrm{eV}$ attributed to the $1 s \rightarrow 3 d$ dipole-forbidden transition of $\mathrm{Fe}$ ions ${ }^{23,24}$ is associated with the symmetry of the crystal field around the $\mathrm{Fe}$ absorbing atom. Tetrahedrally coordinated Fe ions give strong $P_{1}$ intensity, due to the mixture of $p$ and $d$ orbitals in the tetrahedral symmetry, for the case of brownmillerite $\mathrm{Ca}_{2} \mathrm{Fe}_{2} \mathrm{O}_{5}$. Meanwhile, low $\mathrm{P}_{1}$ intensity will be observed for octahedrally coordinated $\mathrm{Fe}$ ions, due to the quadrupole-allowed transition in the octahedral symmetry, for the case of perovskite $\mathrm{LaFeO}_{3}$.

(2) There is a shoulder (labeled $\mathrm{P}_{2}$ in Fig. 4) at around $7119 \mathrm{eV}$, which is ascribed to the $1 s \rightarrow 4 p$ transition with simultaneous ligand-to-metal charge transfer. ${ }^{24}$ Similar to the case of $\mathrm{P}_{1}$, the intensity of $\mathrm{P}_{2}$ is also dependent on the crystal field symmetry. It is strong for brownmillerite-type structure with alternating sheets of $\mathrm{FeO}_{4}$ and $\mathrm{FeO}_{6}$, and weak for other (i.e., Grenier and perovskite) phases. The intensity decreased and the peak shifted towards higher energy for $P_{1}$ and $P_{2}$ with increasing $x$ (Fig. 4 and inset), demonstrating the brownmillerite-to-perovskite transformation through the Grenier phase.

(3) The midpoint of the absorption edge (labeled $E_{\text {exp }}$ ), corresponding to the maximum of the first derivative curve (Fig. 4, lower panel), correlates with the valence state of $\mathrm{Fe}$ atoms, being about $7123 \mathrm{eV}$ for the parent $\mathrm{Ca}_{2} \mathrm{Fe}_{2} \mathrm{O}_{5}(x=0)$. This value is the same as the $E_{0}$ value of $\mathrm{Fe}^{3+}$ in $\mathrm{Fe}_{2} \mathrm{O}_{3}$. However, with increasing $x, E_{\exp }$ tended to shift towards higher energy corresponding to $\mathrm{Fe}^{4+}$, being about $7125 \mathrm{eV}$ for $x=1$, as presented in Table I.

The local geometric structure around Fe ions can be determined by plotting the Fourier-transformed (FT) spectra of the extended x-ray absorption fine structure (EXAFS) region. Specifically, the FT spectra of the $\mathrm{Ca}_{2-x} \mathrm{La}_{x} \mathrm{Fe}_{2} \mathrm{O}_{5+\delta}$ compounds (Fig. 5) showed a strong peak centered at about $1.5 \AA$, corresponding to the average bond distance of $\mathrm{Fe}-\mathrm{O}$ $\left(R_{\mathrm{Fe}-\mathrm{O}}\right)$. Due to the phase shift of photoelectron backscattering, this peak was shifted by $\sim 0.5 \AA$ on the $R$ axis from the standard value. ${ }^{25}$ Table I also presents the average values of $R_{\mathrm{Fe}-\mathrm{O}}$ estimated for the $\mathrm{Ca}_{2-x} \mathrm{La}_{x} \mathrm{Fe}_{2} \mathrm{O}_{5+\delta}$ compounds. In previous work, Ryu et al. ${ }^{24}$ showed that the $\mathrm{Fe}-\mathrm{O}$ distances in the parent $\mathrm{Ca}_{2} \mathrm{Fe}_{2} \mathrm{O}_{5}$ lie in the range of $1.963 \AA$ to $1.977 \AA$ for $\mathrm{Fe}-\mathrm{O}_{6}$ and $1.884 \AA$ to $1.858 \AA$ for $\mathrm{FeO}_{4}$. Their average distance of $\sim 1.911 \AA$ is very close to the value $R_{\mathrm{Fe}-\mathrm{O}}=1.910 \AA$ obtained for our $\mathrm{Ca}_{2} \mathrm{Fe}_{2} \mathrm{O}_{5}$ compound. In particular, with increasing $x$, there was a gradual increase of $R_{\mathrm{Fe}-\mathrm{O}}$ from $1.924 \AA$ for $x=0.1$ to $2.001 \AA$ for $x=1$, as shown in Table I. This enhancement of $R_{\mathrm{Fe}-\mathrm{O}}$ is related to the structural transformation tendency from $\mathrm{Ca}_{2} \mathrm{Fe}_{2} \mathrm{O}_{5}$ through $\mathrm{LaCa}_{2} \mathrm{Fe}_{3} \mathrm{O}_{8}$ to $\mathrm{LaFeO}_{3}$, because the perovskite 


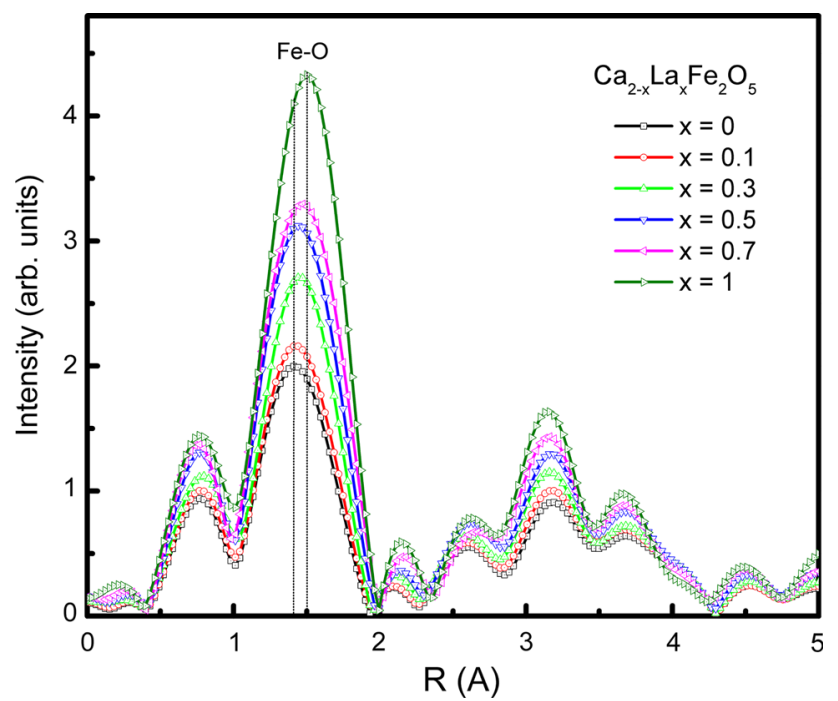

Fig. 5. $k^{3}$-weighted FT EXAFS spectra collected at the Fe K-edge for typical $\mathrm{Ca}_{2-x} \mathrm{La}_{x} \mathrm{Fe}_{2} \mathrm{O}_{5+\delta}$ compounds.

$\mathrm{LaFeO}_{3}$ contains only $\mathrm{FeO}_{6}$ octahedron with $R_{\mathrm{Fe}-}$ $\mathrm{o}=1.974 \AA$ to $2.006 \AA$, ${ }^{24,26}$ fairly close to the $R_{\mathrm{Fe}-\mathrm{O}}$ values of our compounds with $x=0.7$ and 1 .

Together with the peak shift of $R_{\mathrm{Fe}-\mathrm{O}}$, its intensity also increased with increasing $x$ in the $\mathrm{Ca}_{2-x} \mathrm{La}_{x-}$ $\mathrm{Fe}_{2} \mathrm{O}_{5+\delta}$ compounds. This is thought to be due to an increase in the coordination number of oxygen atoms surrounding the $\mathrm{Fe}$ atom, because the EXAFS spectrum is the sum of outgoing and incoming waves, which depend on the immediate environment of the absorbing atom. ${ }^{25}$ In other words, $\delta$ in $\mathrm{Ca}_{2-x} \mathrm{La}_{x} \mathrm{Fe}_{2} \mathrm{O}_{5+\delta}$ tends to increase with increasing $x$, in good agreement with the XRD analysis above. In summary, the studies of the geometric and electronic structures demonstrate that: (1) only $\mathrm{Fe}^{3+}$ ions are present in $\mathrm{Ca}_{2} \mathrm{Fe}_{2} \mathrm{O}_{5}$ $(x=0),(2)$ both $\mathrm{Fe}^{3+}$ and $\mathrm{Fe}^{4+}$ ions coexist in $\mathrm{Ca}_{2-x} \mathrm{La}_{x} \mathrm{Fe}_{2} \mathrm{O}_{5+\delta}$ with $x>0$, (3) the concentration of $\mathrm{Fe}^{4+}$ ions tends to increase with increasing $x$, and these ions are thought to be favored in the Grenier and perovskite structures, and (4) increase of $x$ above 0.05 leads to the structural phase transformation $\mathrm{Ca}_{2} \mathrm{Fe}_{2} \mathrm{O}_{5} \rightarrow \mathrm{LaCa}_{2} \mathrm{Fe}_{3} \mathrm{O}_{8} \rightarrow \mathrm{LaFeO}_{3}$, due to the increase of the oxygen content. These changes directly influence the magnetic and electrical properties of the $\mathrm{Ca}_{2-x} \mathrm{La}_{x} \mathrm{Fe}_{2} \mathrm{O}_{5+\delta}$ compounds.

\section{Magnetic Properties}

The magnetic properties of the $\mathrm{Ca}_{2-x} \mathrm{La}_{x} \mathrm{Fe}_{2} \mathrm{O}_{5+\delta}$ compounds at room temperature were studied by means of ESR and magnetization measurements. Their ESR spectra indicated that the signal intensity (Int) was very weak for $x=0$, but became strong on increasing $x$ from 0.05 to 1 (Figs. 6 and 7a). Concurrently, the spectral line width $(\Delta H)$ and resonant field $\left(H_{\mathrm{r}}\right)$ also changed (Fig. $7 \mathrm{~b}$ and c). In our work, the $H_{\mathrm{r}}$ values (3040 Oe to $3200 \mathrm{Oe}$ ) are

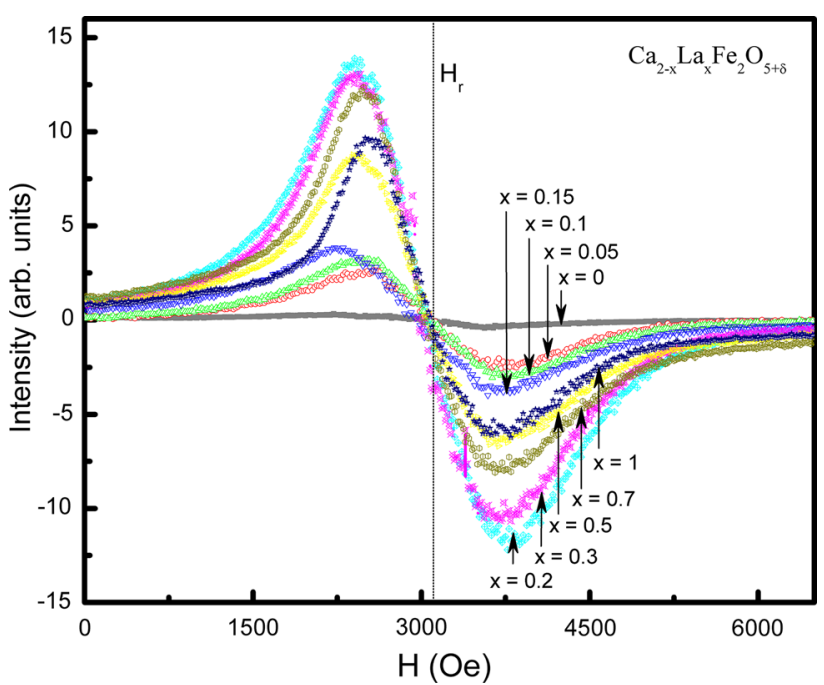

Fig. 6. Room-temperature ESR spectra of the $\mathrm{Ca}_{2-x} \mathrm{La}_{x} \mathrm{Fe}_{2} \mathrm{O}_{5+\delta}$ compounds.

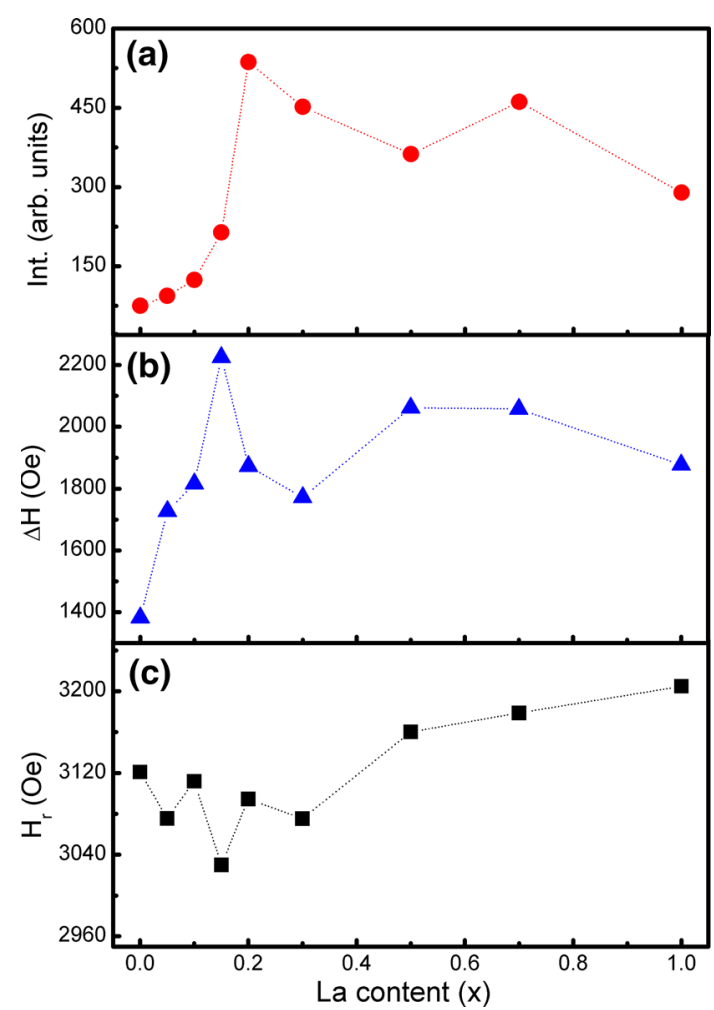

Fig. 7. Variation of ESR spectral parameters for $\mathrm{Ca}_{2-x} \mathrm{La}_{x} \mathrm{Fe}_{2} \mathrm{O}_{5+\delta}$ compounds as function of $x$ : (a) Int, (b) $\Delta H$, and (c) $H_{\mathrm{r}}$.

smaller than the $H_{\mathrm{r}}$ value of free/unpaired electrons $(\sim 3300 \mathrm{Oe}),{ }^{27}$ and depend on $x$. This proves that the resonant signals mainly arise from FM and/or AFM coupling between the magnetic moments of $\mathrm{Fe}^{3+}$ and $\mathrm{Fe}^{4+}$ ions. For the parent compound $\mathrm{Ca}_{2} \mathrm{Fe}_{2} \mathrm{O}_{5} \quad(x=0)$, its weak intensity indicates $\mathrm{Fe}^{3+}-\mathrm{Fe}^{3+}$ AFM pairs persisting up to 


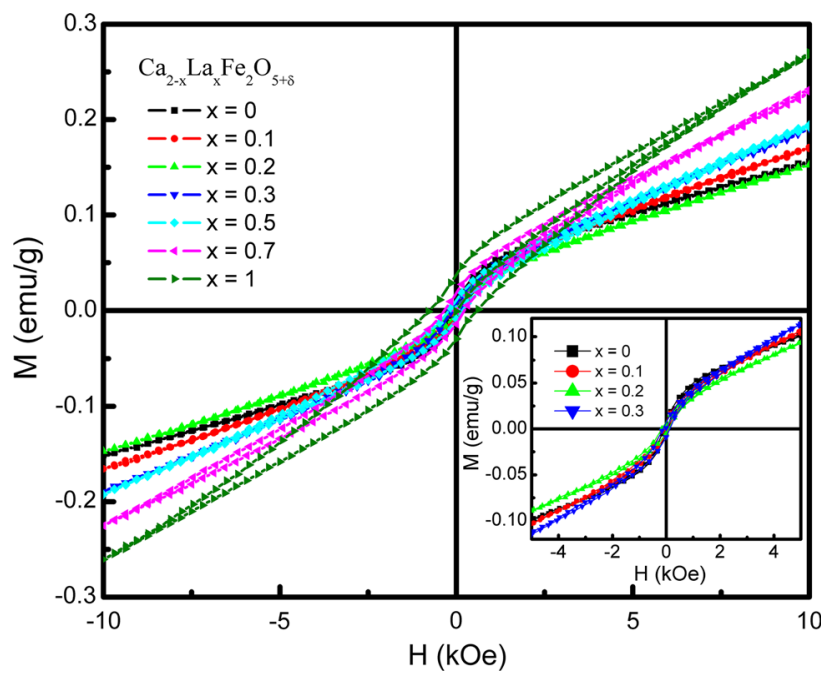

Fig. 8. Room-temperature $M(H)$ loops of typical $\mathrm{Ca}_{2-x} \mathrm{La}_{x} \mathrm{Fe}_{2} \mathrm{O}_{5+\delta}$ compounds. Inset shows enlarged view of $M(H)$ curves for the compounds with $x=0$ to 0.3 .

$T_{\mathrm{N}} \approx 700 \mathrm{~K},{ }^{8-10}$ because only $\mathrm{Fe}^{3+}$ ions are present in this compound. With increasing $x$ from 0.05 to 0.2 , in which range the brownmillerite and Grenier phases coexist, the appearance of $\mathrm{Fe}^{4+}$ ions results in $\mathrm{Fe}^{3+}-\mathrm{Fe}^{4+} \mathrm{FM}$ and $\mathrm{Fe}^{4+}-\mathrm{Fe}^{4+} \mathrm{AFM}$ exchange pairs, enhancing Int. For the compounds with $x>0.2$, the complex variations in the spectral parameters are related to the coexistence of the Grenier and perovskite phases, and creation of more $\mathrm{Fe}^{4+}-\mathrm{Fe}^{4+}$ AFM pairs in addition to $\mathrm{Fe}^{3+}-\mathrm{Fe}^{4+} \mathrm{FM}$ pairs. Here, the different variation tendencies of Int, $\Delta H$, and $H_{\mathrm{r}}$ are due to their different nature and depend on the volume fractions of the crystal phases in the compounds. While Int is mainly associated with the magnetic susceptibility, $\Delta H$ is associated with the total magnetic moments that contribute to resonance. Meanwhile, $H_{\mathrm{r}}$ is dependent on the Landé $g$-factor characteristic of spin-spin and spin-orbit couplings ${ }^{27}$ of $\mathrm{Fe}^{3+}$ and $\mathrm{Fe}^{4+}$ ions. Obviously, together with EXAFS studies, use of ESR spectroscopy as an auxiliary tool is very helpful to detect small changes in the concentration of $\mathrm{Fe}^{4+}$ in $\mathrm{Ca}_{2-x} \mathrm{La}_{x} \mathrm{Fe}_{2} \mathrm{O}_{5+\delta}$, particularly for the compounds with $x=0.05$ to 0.2 .

Considering the $M(H)$ results (Fig. 8), it emerges that all the $\mathrm{Ca}_{2-x} \mathrm{La}_{x} \mathrm{Fe}_{2} \mathrm{O}_{5+\delta}$ compounds exhibit magnetic hysteresis loops with weak FM/AFM order at room temperature. These $M(H)$ data can be divided into two characteristic groups. The first group includes the compounds with $x \leq 0.3$, whose loop areas at magnetic fields $H<2 \mathrm{kOe}$ are narrow; at higher fields, no loop is observed and $M$ increases linearly with increasing $H$. The other group includes the compounds with $x>0.3$, whose loop areas are much larger than those of the first group; at magnetic fields $H>7 \mathrm{kOe}$, there is no hysteresis loop and the $M(H)$ dependences are linear. Such linear $M(H)$ dependence at high field could be

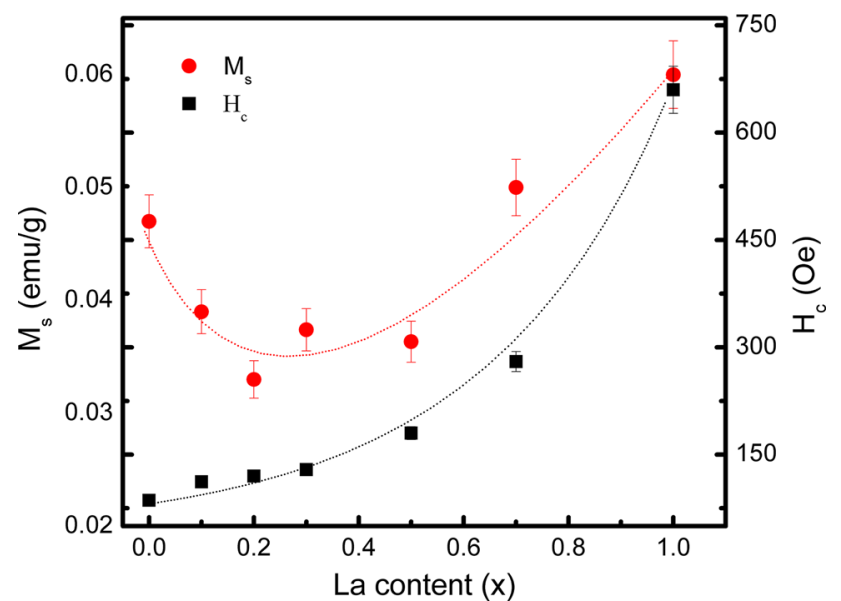

Fig. 9. $M_{\mathrm{s}}$ and $H_{\mathrm{c}}$ versus $x$ in $\mathrm{Ca}_{2-x} \mathrm{La}_{x} \mathrm{Fe}_{2} \mathrm{O}_{5+\delta}$. Dotted lines are guides to the eye only; $5 \%$ error bars are shown.

related to various effects such as (1) the magnetic moments in FM/AFM regions have not yet reached saturation state, (2) short-range FM order, and/or (3) paramagnetism of isolated $\mathrm{Fe}^{3+, 4+}$ ions. For the hysteresis loop regions associated with FM/AFM interactions, one can analyze the $x$ dependence of the saturation magnetization $\left(M_{\mathrm{r}}\right)$ and coercivity $\left(H_{\mathrm{r}}\right)$, as shown in Fig. 9. For the first group, $M_{\mathrm{r}}$ gradually decreased from $0.047 \mathrm{emu} / \mathrm{g}$ for $x=0$ to $\sim 0.038 \mathrm{emu} / \mathrm{g}$ for $x=0.3$, while $H_{\mathrm{c}}$ changed less (86 Oe to 129 Oe). However, for the second group, both $M_{\mathrm{s}}$ and $H_{\mathrm{c}}$ increased rapidly with increasing $x$ from 0.4 to 1 . These variations of $M_{\mathrm{s}}$ and $H_{\mathrm{c}}$ are associated with the changes in the $\mathrm{Fe}^{3+} / \mathrm{Fe}^{4+}$ ratio and structural phases. As mentioned above, brownmillerite phase is dominant for $x<0.3$, where the $\mathrm{Fe}^{3+}-\mathrm{Fe}^{3+} \mathrm{AFM}$ interaction plays a pivotal role. The appearance of $\mathrm{Fe}^{4+}$ leads to addition of the $\mathrm{Fe}^{3+}-$ $\mathrm{Fe}^{4+} \mathrm{FM}$ interaction, which competes with the AFM one, slightly reducing $M_{\mathrm{s}}$. For the Grenier phase with dominantly AFM-ordered $\mathrm{Fe}^{3+}$ ions, ${ }^{18}$ we believe that the presence of $\mathrm{Fe}^{4+}$ in this structure also does not enhance $M_{\mathrm{s}}$ and $H_{\mathrm{c}}$, because its volume fraction is relatively large, in the range of $x=0.1$ to 0.3 . However, for the compounds with $x>0.3$, higher $x$ results in development of perovskite phase, creating more $\mathrm{Fe}^{3+}-\mathrm{Fe}^{4+} \mathrm{FM}$ pairs. These factors enhance $M_{\mathrm{s}}$ and $H_{\mathrm{c}}$, similar to the case of $\mathrm{La}_{1-x} \mathrm{Ca}_{x-}$ $\mathrm{FeO}_{3}$ compounds. ${ }^{28,29}$ In other words, the enhanced FM behavior for $x>0.3$ is related to $\mathrm{Fe}^{4+}$ ions in the perovskite rather than brownmillerite or Grenier structure. Although $\mathrm{Fe}^{3+}-\mathrm{Fe}^{4+} \mathrm{FM}$ pairs are present in the $\mathrm{Ca}_{2-x} \mathrm{La}_{x} \mathrm{Fe}_{2} \mathrm{O}_{5+\delta}$ compounds with $x>0.3$, the AFM interaction due to $\mathrm{Fe}^{3+}-\mathrm{Fe}^{3+}$ and $\mathrm{Fe}^{4+}-$ $\mathrm{Fe}^{4+}$ pairs remains dominant. The narrowing of the $M(H)$ loop for fields $H<2.5 \mathrm{kOe}$ for $x=1$ is thus ascribed to competition between the two FM and AFM phases in different crystal phases. The variation tendency of $M_{\mathrm{S}}$ (Fig. 9) and $H_{\mathrm{r}}$ (Fig. 7c) versus $x$ is more or less the same. This is due to their 
correlation to FM resonance, as described by the Kittel formulae. ${ }^{30}$

\section{Electrical Properties}

We measured the resistivity, $\rho$, of the $\mathrm{Ca}_{2-x} \mathrm{La}_{x}$ $\mathrm{Fe}_{2} \mathrm{O}_{5+\delta}$ compounds in the temperature range of $T=20 \mathrm{~K}$ to $400 \mathrm{~K}$. However, the $\rho$ for the compounds with $x=0$ and 0.05 was above $5 \times 10^{6} \Omega \mathrm{cm}$, lying beyond the measurement range of our device. For the other compounds $(x \geq 0.1)$, we recorded their resistivity at temperatures of $T>120 \mathrm{~K}$, as shown in Fig. 10. Depending on $x$ and $T$ (from $120 \mathrm{~K}$ to $400 \mathrm{~K}$ ), $\rho$ varied over a wide range from $1 \Omega \mathrm{cm}$ to $10^{6} \Omega \mathrm{cm}$. For given $x$ value, $\rho$ decreased exponentially with increasing $T$, being a typical characteristic of semiconductors. In particular, the $\rho-T$ dependences can be described based on the adiabatic small polaron hopping ( $\mathrm{SPH}$ ) model formulated as

$$
\rho(T)=\rho_{0} \exp \left(\frac{E_{\mathrm{a}}}{k_{\mathrm{B}} T}\right),
$$

where $E_{\mathrm{a}}$ is the polaron formation energy and $k_{\mathrm{B}}$ is the Boltzmann constant. The resistivity coefficient $\rho_{0}$ can be determined from the following equation:

$$
\rho_{0}=\frac{k_{\mathrm{B}}}{n(1-x) e^{2} d},
$$

where $n$ is the charge carrier density, $x$ is the hole $\left(\mathrm{Fe}^{4+}\right)$ concentration, and $d$ is the polaron diffusion constant, which depends on the lattice constants and the characteristic frequency of the longitudinal optical (LO) phonon carrying polarons through the lattice. $^{31}$ The motion of charge carriers in the adiabatic region is considered to be faster than lattice vibrations. Using Eq. 2 to fit the $\rho(T)$ data in the range of $T=130 \mathrm{~K}$ to $400 \mathrm{~K}$ (Fig. 11), we determined the values of $E_{\text {a }}$, as shown in Table I and the inset of Fig. 11. The results reveal that $E_{\mathrm{a}}$ varied as a function of $x$, being $123.8 \mathrm{meV}$ for $x=0.1$ but decreasing rapidly to $94.8 \mathrm{meV}$ for $x=0.2$. In the range of $x=0.3$ to $0.7, E_{\mathrm{a}}(95 \mathrm{meV}$ to $97 \mathrm{meV})$ remained relatively unchanged, but slightly increased at $x=1$. These values indicate a close relation between $\rho, E_{\mathrm{a}}$, and $\mathrm{Fe}^{4+}$ ions. In other words, the decrease in $\rho$ is due to an increase in the $\mathrm{Fe}^{4+}$ concentration (with increased density of charge carriers) that reduces $E_{\mathrm{a}}$. Small polarons involved in nearest-neighbor hopping become more mobile versus thermal activation processes. Recently, Malveiro et al. ${ }^{14}$ studied brownmillerite $\mathrm{Ca}_{2} \mathrm{FeAl}_{1-x}$ $\mathrm{Mg}_{x} \mathrm{O}_{5}(x=0$ and 0.05$)$, finding large values of $E_{\mathrm{a}}$ (260 meV to $620 \mathrm{meV}$ ), which tended to decrease if more $\mathrm{Fe}^{4+}$ ions were added to the brownmillerite lattice. Apart from the important role of $\mathrm{Fe}^{4+}$ ions, we believe that structural changes and grainboundary-related effects also influence $\rho$ and $E_{\text {a }}$,

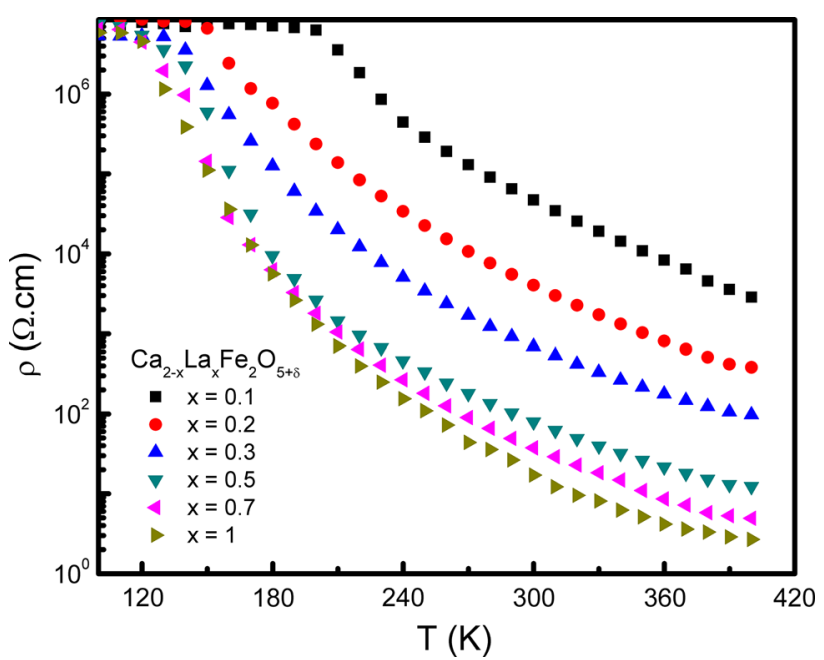

Fig. 10. Temperature-dependent resistivity, $\rho(T)$, of $\mathrm{Ca}_{2-x} \mathrm{La}_{x}$ $\mathrm{Fe}_{2} \mathrm{O}_{5+\delta}$ compounds $(x \geq 0.1)$ as function of $x$.

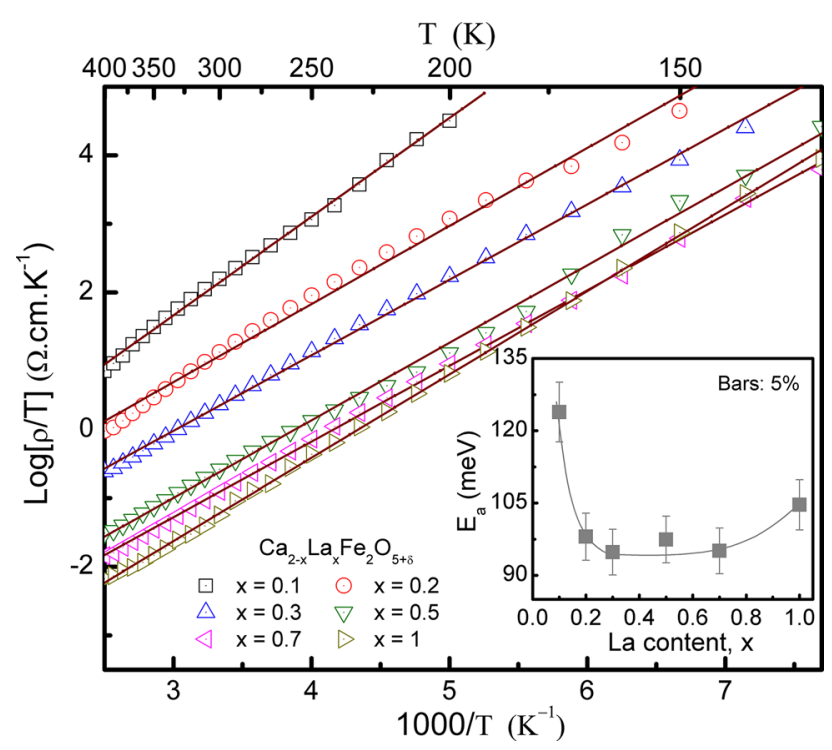

Fig. 11. $\log (\rho / T)$ versus $1000 / T$ data (symbols) of $\mathrm{Ca}_{2-x} \mathrm{La}_{x} \mathrm{Fe}_{2} \mathrm{O}_{5+\delta}$ compounds with $x>0.1$ fit to the SPH model (solid lines, Eq. 2). Inset shows $x$ dependence of $E_{\mathrm{p}}$ varying on the meV scale; the solid line is a guide to the eye only.

because the LO phonon frequency and the hopping of polarons would be modified by these factors. ${ }^{14,32}$

\section{CONCLUSIONS}

Detailed analysis of the XRD patterns, Fe K-edge XANES spectra, and ESR spectra of $\mathrm{Ca}_{2-x} \mathrm{La}_{x}$ $\mathrm{Fe}_{2} \mathrm{O}_{5+\delta}$ compounds ( $x=0$ to 1 ) at room temperature revealed the following: (1) only $\mathrm{Fe}^{3+}$ ions exist in the parent $\mathrm{Ca}_{2} \mathrm{Fe}_{2} \mathrm{O}_{5}(x=0)$, (2) there is a mixture of $\mathrm{Fe}^{3+}$ and $\mathrm{Fe}^{4+}$ ions in $\mathrm{Ca}_{2-x} \mathrm{La}_{x} \mathrm{Fe}_{2} \mathrm{O}_{5+\delta}$ with $x>0$, (3) the $\mathrm{Fe}^{4+}$ content tends to increase with increasing $x$, and these $\mathrm{Fe}^{4+}$ ions preferably locate in the Grenier $\mathrm{LaCa}_{2} \mathrm{Fe}_{3} \mathrm{O}_{8}$ and perovskite $\mathrm{LaFeO}_{3}$ structures, and (4) increase of $x$ from 0.1 to 1 causes a 
structural phase transformation due to the increasing oxygen and $\mathrm{Fe}^{4+}$ contents. $M(H)$ measurements at room temperature also revealed magnetic phase separation with two characteristic groups. For the first group, $M_{\mathrm{r}}$ gradually decreased from $0.047 \mathrm{emu} /$ $\mathrm{g}$ for $x=0$ to $\sim 0.038 \mathrm{emu} / \mathrm{g}$ for $x=0.3$, while $H_{\mathrm{c}}$ changed less ( 86 Oe to 129 Oe). However, for the second group, both $M_{\mathrm{s}}$ and $H_{\mathrm{c}}$ increased rapidly with increasing $x$ from 0.4 to 1 . These variations of $M_{\mathrm{S}}$ and $H_{\mathrm{c}}$ are tightly related to the changes in the $\mathrm{Fe}^{3+} / \mathrm{Fe}^{4+}$ ratio and structural phases. Study of the temperature-dependent resistivity in the range of $T=20 \mathrm{~K}$ to $400 \mathrm{~K}$ revealed that all the compounds are insulators. Although the $\rho(T)$ values for the compounds with $x=0$ and 0.05 lay beyond our measurement capability of $5 \times 10^{6} \Omega \mathrm{cm}$, the compounds with $x \geq 0.1$ showed lower $\rho(T)$ values that decreased with increasing $x$ from 0.1 to 1 and $T$ from $120 \mathrm{~K}$ to $400 \mathrm{~K}$. We also found that the $\rho(T)$ data for $x \geq 0.1$ obeyed the adiabatic SPH model, with rapidly decreasing polaron formation energy $E_{\mathrm{a}}$ for $x>0.1$. Apart from the important role of $\mathrm{Fe}^{4+}$ ions, structural changes and grain-boundary-related effects are also thought to influence $\rho$ and $E_{\mathrm{a}}$.

\section{ACKNOWLEDGEMENTS}

This research was supported by the Basic Science Research Program (NRF-2014R1A2A1A11051245, NRF-2017R1A2B4010490), and the International Cooperation Program (NRF-2015K2A1A2071001), through the National Research Foundation of Korea, funded by the Ministry of Education, Science, and Technology.

\section{REFERENCES}

1. Q. Lu and B. Yildiz, Nano Lett. 16, 1186 (2016).

2. C.P. Jijil, M. Lokanathan, S. Chithiravel, C. Nayak, D. Bhattacharyya, S.N. Jha, P.D. Babu, B. Kakade, and R.N. Devi, ACS Appl. Mater. Interfaces 8, 34387 (2016).

3. M.D. Rossell, O.I. Lebedev, G. Van Tendeloo, N. Hayashi, T. Terashima, and M. Takano, J. Appl. Phys. 95, 5145 (2004).

4. M. Ismail, W. Liu, M.S.C. Chan, M.T. Dunstan, and S.A. Scott, Energy Fuels 30, 6220 (2016).

5. K. Gupta, S. Singh, and M.S.R. Rao, Nano Energy 11, 146 (2014).

6. T.C. Gibb, A.J. Herod, D.C. Munro, and N. Peng, J. Mater. Chem. 4, 1451 (1994).
7. J.M. Gonzalez-Calbet, M. Vallet-Regi, and M.A. AlarioFranco, J. Solid State Chem. 60, 320 (1985).

8. T. Takeda, Y. Yamaguchi, S. Tomiyoshi, M. Fukase, M. Sugimoto, and H. Watanabe, J. Phys. Soc. Jpn. 24, 446 (1968).

9. K. Gupta, S. Singh, M. Ceretti, M.S.R. Rao, and W. Paulus, Phys. Status Solidi A 210, 1771 (2013).

10. T. Labii, M. Ceretti, A. Boubertakh, W. Paulus, and S. Hamamda, J. Therm. Anal. Calorim. 112, 865 (2013).

11. D. Petrov and B. Angelov, Acta Phys. Pol. A 122, 737 (2012).

12. D. Petrov, B. Angelov, and V. Lovchinov, J. Alloys Compd. 509, 5038 (2011).

13. P.M. Woodward, D.E. Cox, E. Moshopoulou, A.W. Sleight, and S. Morimoto, Phys. Rev. B 62, 844 (2000).

14. J. Malveiro, T. Ramos, L.P. Ferreira, J.C. Waerenborgh, M.R. Nunes, M. Godinho, and M.D. Carvalho, J. Solid State Chem. 180, 1863 (2007).

15. S. Dhankhar, K. Gupta, G. Bhalerao, N. Shukla, M. Chandran, B. Francis, B. Tiwari, K. Baskar, and S. Singh, RSC Adv. 5, 92549 (2015).

16. N. Abe, N.D. Khanh, T. Sasaki, and T. Arima, Phys. Rev. B 89, 054437 (2014).

17. J.A. Bearden and A.F. Burr, Rev. Mod. Phys. 39, 125 (1967).

18. J.M. Hudspeth, D.J. Goossens, A.J. Studer, R.L. Withers, and L. Norén, J. Phys. Condens. Matter 21, 124206 (2009).

19. P.M. Price, N.D. Browning, and D.P. Butt, J. Am. Ceram. Soc. 98, 2248 (2015).

20. C. Didier, J. Claridge, and M. Rosseinsky, J. Solid State Chem. 218, 38 (2014).

21. I.V. Spesivtseva, N.A. Kochetova, E.M. Gorbunova, and I.E. Animitsa, Russ. J. Phys. Chem. A 85, 1816 (2011).

22. G.J. Redhammer, G. Tippelt, G. Roth, and G. Amthauer, Am. Miner. 89, 405 (2004).

23. A.E. True, R.C. Scarrow, C.R. Randall, R.C. Holz, and L. Que Jr, J. Am. Chem. Soc. 115, 4246 (1993).

24. K.H. Ryu, K. Sakaue, H. Terauchi, and C.H. Yo, Bull. Korean Chem. Soc. 18, 1047 (1997).

25. B.K. Teo, Basic Principles and Data Analysis (Berlin: Springer, 1986).

26. M. Marezio and P.D. Dernier, Mater. Res. Bull. 6, 23 (1971)

27. M. Ikeya, New Applications of Electron Spin Resonance (Singapore: World Scientific, 1993).

28. Z.C. Xu, M.F. Liu, C.C. Chen, and X.N. Ying, J. Appl. Phys. 115,123516 (2014).

29. E.K. Abdel-Khalek and H.M. Mohame, Hyperfine Interact. 222, S57 (2013).

30. C. Kittel, Introduction to Solid State Physics, 8th ed. (Hoboken: Wiley, 2004).

31. D. Varshney and N. Dodiya, J. Theor. Appl. Phys. 9, 45 (2015).

32. W. Luo, H.M. Yao, P.H. Yang, and C.S. Chen, J. Am. Ceram. Soc. 92, 2682 (2009). 